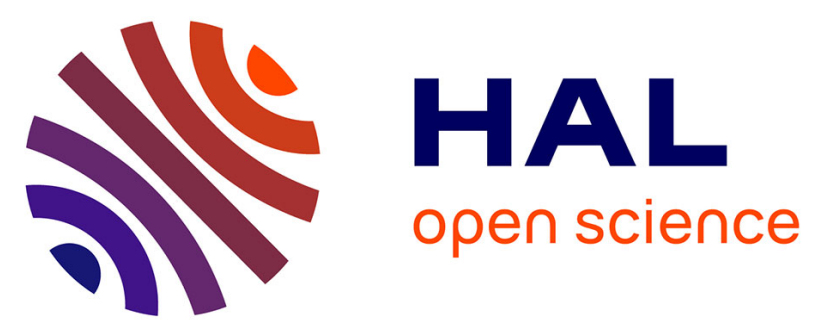

\title{
Sequential focused ion beam scanning electron microscopy analyses for monitoring cycled-induced morphological evolution in battery composite electrodes. Silicon-graphite electrode as exemplary case
}

Victor Vanpeene, Patrick Soucy, Jianhan Xiong, Nicolas Dupré, Bernard Lestriez, Lionel Roué

\section{To cite this version:}

Victor Vanpeene, Patrick Soucy, Jianhan Xiong, Nicolas Dupré, Bernard Lestriez, et al.. Sequential focused ion beam scanning electron microscopy analyses for monitoring cycled-induced morphological evolution in battery composite electrodes. Silicon-graphite electrode as exemplary case. Journal of Power Sources, 2021, 498, pp.229904. 10.1016/j.jpowsour.2021.229904 hal-03266337

\section{HAL Id: hal-03266337 https://hal.science/hal-03266337}

Submitted on 29 Jun 2021

HAL is a multi-disciplinary open access archive for the deposit and dissemination of scientific research documents, whether they are published or not. The documents may come from teaching and research institutions in France or abroad, or from public or private research centers.
L'archive ouverte pluridisciplinaire HAL, est destinée au dépôt et à la diffusion de documents scientifiques de niveau recherche, publiés ou non, émanant des établissements d'enseignement et de recherche français ou étrangers, des laboratoires publics ou privés. 
Sequential focused ion beam scanning electron microscopy analyses for monitoring cycledinduced morphological evolution in battery composite electrodes. Silicon-graphite electrode as exemplary case.

\author{
Victor Vanpeene ${ }^{\mathrm{a}}$, Patrick Soucy ${ }^{\mathrm{a}}$, Jianhan Xiong ${ }^{\mathrm{b}}$, Nicolas Dupré ${ }^{\mathrm{b}}$, Bernard Lestriez ${ }^{\mathrm{b}, *}$, Lionel \\ Roué, ${ }^{\mathrm{a}, *}$
}

a Institut National de la Recherche Scientifique (INRS) - Centre Énergie, Matériaux, Télécommunications (EMT), J3X 1S2 Varennes (QC) Canada.

${ }^{b}$ Université de Nantes, CNRS, Institut des Matériaux Jean Rouxel, IMN, F-44000 Nantes, France.

*Corresponding authors: roue@emt.inrs.ca (L. Roué) bernard.lestriez@cnrs-imn.fr (B. Lestriez) 


\begin{abstract}
In the present work, an alternative to the standard ex-situ and destructive focused ion beam scanning electron microscopy (FIB/SEM) analysis procedure is demonstrated for monitoring the morphological degradation of a single $\mathrm{Si} /$ graphite (1/1 mass ratio) blended electrode for Li-ion batteries. For this purpose, a FIB milled microcavity is created in the pristine electrode, which is observed in FIB- polished cross section by SEM at different cycling periods (pristine, $1^{\text {st }}, 9^{\text {th }}$ and $50^{\text {th }}$ cycles). This allows studying the same cycled electrode as for an in-situ method. Its cyclinginduced morphological change is characterized at the electrode and particle scales by monitoring the evolution of the electrode thickness, mass and porosity, the Si particle morphology, Si interparticle distance, surface fraction and twisting of the graphite flakes. This is correlated to the evolution of the electrode discharge capacity and impedance. As a result, a more comprehensive view of the degradation phenomena of the Si/graphite blended electrode is established.
\end{abstract}

Keywords: lithium-ion battery, silicon-graphite electrode, FIB-SEM, morphological degradation 


\section{Introduction}

The demand for electric vehicles with a large driving range $(+500 \mathrm{~km})$ has pushed forward the requirement to increase the energy density of Li-ion batteries. For that purpose, various anode and cathode materials are under development for replacing the common commercial NMC and NCA/graphite systems [1-3]. In this context, silicon with its very high specific capacity

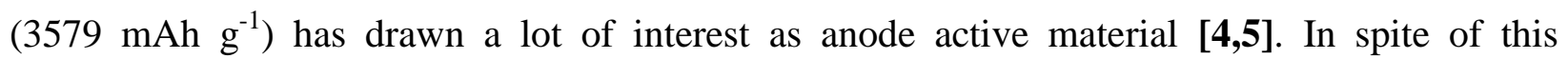
attractive aspect, silicon based anodes have faced multiple hurdles on the way to their commercialization, such as a severe capacity fading and high initial irreversible capacity loss, resulting from important volume variations undergone by the silicon particles upon (de)alloying with lithium [6]. The different degradation mechanisms identified, such as the pulverization of the active material [7], continuous formation of an unstable solid electrolyte interphase (SEI) on the Si particles [8], and electrode macro-cracking and delamination from its current collector [9], have been extensively studied in order to overcome their detrimental consequences on the cycle life of the electrode. A large panel of strategies have been proposed [6], partially solving these problems, but the implementation of Si-based anodes in full cell configurations remains problematic $[\mathbf{1 0 , 1 1 ]}$.

The blending of Si particles with graphite is a simple and efficient way to improve the electrode performance, while still providing a higher capacity than graphite alone [12]. In fact, the graphite has a beneficial role by mitigating the mechanical and electrical degradation of the electrode resulting from the volume change of silicon, and furthermore increases the initial coulombic efficiency. The weight ratio of silicon to graphite in the electrode formulation has been increased over the years from $5-10 \%[13,14]$ to $40 \%$ [15] in order to maximize the electrode capacity. According to the calculation of Andre et al., an increase of about $20 \%$ in 
gravimetric and $25 \%$ in volumetric energy density can be achieved using a silicon content of 30\% [3]. Higher Si/graphite ratios deliver a minor increase in volumetric energy density, on one hand because of the increased porosity demand to accommodate the $\mathrm{Si}$ volume expansion together with the increasing anode potential, and on the other hand because the anode volume stands for only typically a third of the total cell volume [3]. However, in present commercial Sigraphite electrodes, the $\mathrm{Si}$ amount is typically around $2-5 \mathrm{wt} . \%$ and the implementation of Siricher anodes in commercial Li-ion batteries remains challenging.

The electrochemical behavior of $\mathrm{Si}$, but also that of graphite, is likely to be affected by the overall volume change of the Si/graphite electrode upon cycling. Better understanding of the failure mechanisms of both $\mathrm{Si}$ and graphite components and their possible interrelation (not yet clearly elucidated) is thus required for optimizing their formulation and processing. To date, even if the panel of characterization techniques used for studying the morphological evolution of $\mathrm{Si} /$ graphite electrodes is wide, they are either $e x$-situ (and destructive) methods such as scanning electron microscopy (SEM) [15] or scanning transmission electron microscopy (STEM) [16], or they require access to a synchrotron facility when considering X-ray computed tomography (XRCT) as ex-situ $[\mathbf{1 7 , 1 8}]$ and in-situ [19] characterization methods.

In the present work, we propose an alternative to the standard ex-situ and destructive focused ion beam scanning electron microscopy (FIB/SEM) analysis procedure by monitoring the morphological degradation in the bulk of a single Si/graphite electrode thanks to a FIB milled microcavity created in the pristine electrode which is observed in FIB-polished cross section by SEM at different cycling periods (pristine, $1^{\text {st }}, 9^{\text {th }}$ and $50^{\text {th }}$ cycle). This investigation technique leads to reduced implementation cost compared to 3D FIB/SEM tomography and allows following the same electrode along different steps of its cycling, as for any in-situ method. 
Meticulous image analysis allows on the one hand following the degradation at the electrode scale, with its thickness, mass and porosity evolution, and on the other hand, monitoring the evolution of the Si particle morphology, Si inter-particle distance evolution, surface fraction and twisting of the graphite flakes. This thorough characterization allows a deeper understanding of the degradation phenomena of the $\mathrm{Si} /$ graphite blended electrode. This is correlated to the evolution of the electrode resistance determined from electrochemical impedance spectroscopy (EIS).

\section{Experimental}

Materials. The active material was a mixture of Si powder and commercial graphite in a weight ratio of 1:1. The commercial synthetic graphite was SFG-6 grade from Imerys Graphite

\& Carbon (specific BET surface area of $17 \mathrm{~m}^{2} \mathrm{~g}^{-1}$, platelet-like shape with a median size of 3.5 $\mu \mathrm{m}$ and a thickness of about $0.4 \mu \mathrm{m}$, according to the supplier's data). The Si powder was obtained from commercial Si powder (99.96\%, -325 mesh, Materion) ball-milled using an attritor (HD-01 model from Union Process, USA) at $600 \mathrm{rpm}$ under argon atmosphere for $20 \mathrm{~h}$ in a $1400 \mathrm{~cm}^{3}$ stainless steel vessel with $3 \mathrm{~kg}$ of stainless steel balls (diam. $1 / 4$ inch) with a ball-topowder weight ratio of 10:1. The as-milled $\mathrm{Si}$ powder is $\sim 90 \%$ amorphous as determined by Raman spectroscopy [20]. It consists of micrometric agglomerates with a median size around 10 $\mu \mathrm{m}$ (determined by a laser scattering method) made up of sub-micrometric particles more or less welded together. During the slurry homogenization step (see below) the Si agglomerates are broken resulting in a particle median size reduced to $\sim 0.8 \mu \mathrm{m}$. Graphene nanoplatelets $(\mathrm{GnP}$, M15 grade from XGSciences, average diameter $=15 \mu \mathrm{m}$, average thickness $=6-8 \mathrm{~nm}$, surface area $=120-150 \mathrm{~m}^{2} \mathrm{~g}^{-1}$ according to the supplier's data) were used as a conductive additive. 
Polyacrylic acid (PAA, $\mathrm{M}_{\mathrm{w}}=450$ 000, Sigma-Aldrich) was used as binder. $\mathrm{LiOH} . \mathrm{H}_{2} \mathrm{O}$ salt (Sigma-Aldrich) was used to partially neutralize the PAA.

Electrode preparation and cell assembly. A binder solution of $\mathrm{PAAH}_{\mathrm{x}} \mathrm{Li}_{1-\mathrm{x}}$ was prepared by stirring the dried PAA powder and an adjusted quantity of $\mathrm{LiOH} . \mathrm{H}_{2} \mathrm{O}$ in deionized water for at least 5 hours until the $\mathrm{pH}$ stabilized at 4 . The electrode slurry was obtained by mixing all the constituents (a total of $400 \mathrm{mg}$ of dry matter: $43 \%^{\text {wt. }} \mathrm{Si}, 43 \%^{\text {wt. }}$ graphite, $4 \%^{\text {wt. }} \mathrm{GnP}, 10 \%^{\mathrm{wt}}$ $\left.\mathrm{PAAH}_{\mathrm{x}} \mathrm{Li}_{1-\mathrm{x}}\right)$ in the binder solution $(1 \mathrm{~mL})$ for $1 \mathrm{~h}$ at $500 \mathrm{rpm}$ in a silicon nitride bowl $(80 \mathrm{~mL})$ with 3 silicon nitride balls $(9.5 \mathrm{~mm}$ diameter) using a Fritsch 7 Pulverisette planetary mixer. The homogenized slurry was tape cast onto a $25 \mu \mathrm{m}$ thick copper foil using a doctor blade and dried for one night with limited airflow at ambient temperature and then at $120^{\circ} \mathrm{C}$ under vacuum for 2 hours. The electrode was not calendared. The areal mass loading of the electrode $(1 \mathrm{~cm} \mathrm{diam.)}$ was $3.8 \mathrm{mg}$ of active material per $\mathrm{cm}^{2}$, which corresponds to a theoretical areal capacity of 7.5 $\mathrm{mAh}$ per $\mathrm{cm}^{2}$. Prior to the cell assembly, a cavity was created in the center of the electrode by FIB milling as detailed below. The electrode was mounted in a two-electrode Swagelok-type cell, facing a lithium metal (1 mm thick) electrode, acting as a reference and counter electrode. The electrodes were separated with a borosilicate glass-fiber membrane (Whatman GF/D) soaked with an electrolytic solution of $1 \mathrm{M} \mathrm{LiPF}_{6}$ in ethylene carbonate (EC) and dimethyl carbonate (DMC) (1:1) with 10 wt.\% fluoroethylene carbonate (FEC). A spring was placed on the counter electrode side to ensure good contact between the different components of the cell by slightly compressing the cell (load $\sim 6 \mathrm{~N})$.

Electrochemical measurements. The electrode was cycled at room temperature in

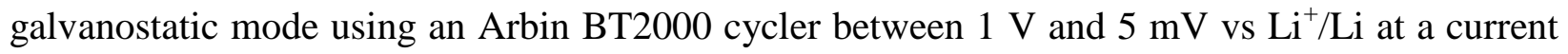
density of $120 \mathrm{~mA} \mathrm{~g}^{-1}$ of active material ( C/16) for the discharge (lithiation), and $240 \mathrm{~mA} \mathrm{~g}^{-1}$ 
( $\sim \mathrm{C} / 8)$ for the charge (delithiation). The capacities are given per gram of active material (i.e. $\mathrm{Si}+$ graphite). Electrochemical impedance spectroscopy (EIS) measurements were also carried out on a sister electrode just after battery assembly and at different lithiation states from the $1^{\text {st }}$ to the $50^{\text {th }}$ cycles. EIS measurements were performed with a three-electrode Swagelok cell, with lithium metal as reference and counter electrodes. Before the EIS measurement, the potential was maintained at the desired value until a very low current was obtained $\left(<10 \mathrm{~mA} \mathrm{~g}^{-1}\right)$. EIS measurements were performed at room temperature, with a $5 \mathrm{mV}$ amplitude excitation and a frequency range from $981 \mathrm{kHz}$ to $10 \mathrm{mHz}$. Between the different EIS acquisitions, the cell was cycled under the same conditions as above. All data acquisitions were performed by using a BioLogic electrochemical workstation and the EIS results were fitted with the Zfit of the EC-lab software.

FIB/SEM. The Si/graphite electrode was studied through FIB/SEM analysis in its pristine state and at the end of its $1^{\text {st }}, 9^{\text {th }}$ and $50^{\text {th }}$ cycles. The FIB/SEM investigation was carried out using a FIB/SEM workstation (Tescan LYRA 3 XMH) combining an FIB column (Ga source) and SEM angled at $55^{\circ}$ from each other (Fig. 1a). The station was also equipped with a multinozzle gas injection system (5-GIS, Orsayphysics). The systematic procedure is detailed according to the scheme of Fig. 1b. 
(a)



(b)

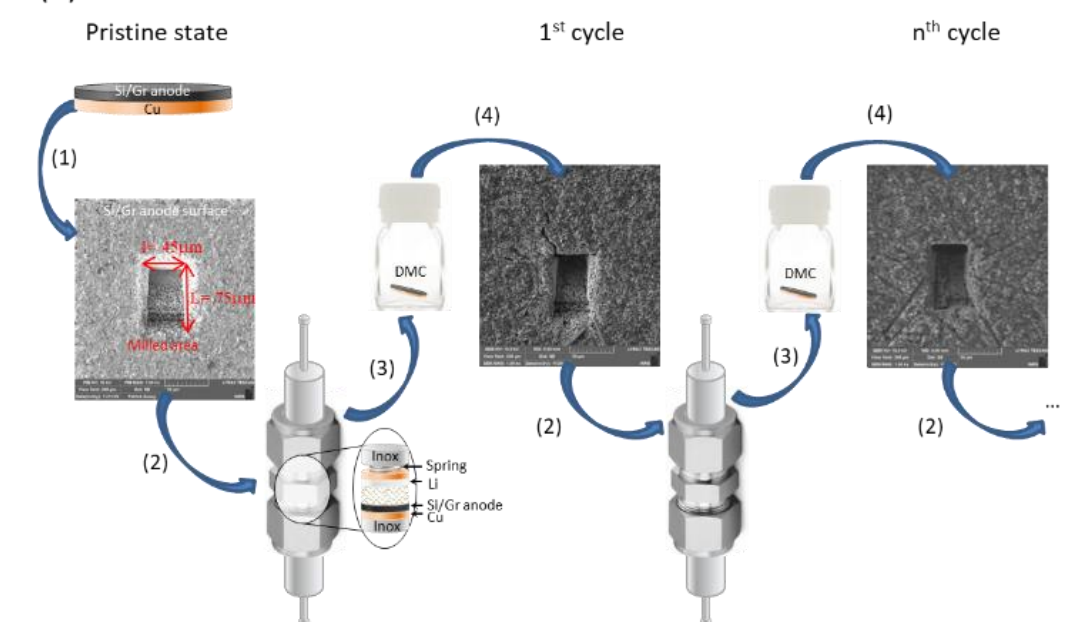

Figure 1. (a) Scheme of the trench milled area and polished surface of the Si/graphite electrode with the FIB/SEM configuration; (b) procedure for FIB/SEM observation at different steps of the electrode cycling.

(1) Prior to cell assembly, a trench of $45 \times 75 \mu \mathrm{m}^{2}$ was milled to a depth of $50 \mu \mathrm{m}$ in the electrode (i.e. down to the $\mathrm{Cu}$ substrate). The schematized view of this trench is depicted in Fig. 1a. This step was performed with a coarse ion beam current of $20 \mathrm{nA}$ with an acceleration voltage of $30 \mathrm{kV}$. This coarse milling allows for quick removal of material but results in uneven milling. Subsequently a gentler polishing step was performed using sequentially a $10 \mathrm{nA}$ ion beam current and finally a current of $860 \mathrm{pA}$ for good cross section rendering and SEM analysis purposes. These steps remove typical artifacts (redeposition of Ga and FIB curtaining) and allow a clear view of the cross section. The video of the trench milling process is available in the supplementary information (see Video S1).

(2) The electrochemical cell was mounted in an Ar filled glove box after the FIB/SEM observation of the pristine state and subsequently cycled for its $1^{\text {st }}$ cycle. 
(3) At the end of the $1^{\text {st }}$ cycle, the cell was dismantled and the electrode was rinsed in a DMC solvent solution for electrolyte removal and then dried at room temperature in an Ar filled glove box. The electrode mass gain was measured before transferring to the FIB/SEM workstation thanks to a sealed transfer chamber. A similar procedure was performed after the $9^{\text {th }}$ and $50^{\text {th }}$ cycles.

(4) The last steps of fine polishing (10 nA and $860 \mathrm{pA}$ ) were reproduced along a $\mathrm{ca} .3 \mu \mathrm{m}$ depth after the $1^{\text {st }}, 9^{\text {th }}$ and $50^{\text {th }}$ cycles to refresh the analysed surface. It is worth noting that after the $9^{\text {th }}$ cycle the lateral border on the left side of the trench collapsed (Fig. $4 \mathbf{a}$ ) and thus required a more advanced polishing step in order to recover the analysed surface. The trench was milled with a $10 \mathrm{nA}$ ion beam current and then polished with $10 \mathrm{nA}$ and $860 \mathrm{pA}$ along a $c a .5 \mu \mathrm{m}$ length (Fig. 4b). After the $50^{\text {th }}$ cycle, the electrode partially delaminated after positioning on the SEM sample holder and thus a different observation zone was chosen (Figs. 4c and d). The milling and polishing procedures were identical to those of the pristine state.

Image segmentation. The pores and solid phase of the electrode were separated by thresholding on the greyscale values of the SEM images. Note that the difference in grey level between the different solid components of the electrode (graphite, Si, PAA, GnP and SEI products) was not sufficient to isolate precisely each of them, thus they are gathered in one segmented part, labelled as the solid phase. In fact, two overlapping peaks were observable on the histograms of the greyscale values of the SEM images (see supplementary Fig. S1a). This allows the isolation of the pores by selecting the lower greyscale values. The result before and after image segmentation is shown in supplementary Fig. S1b-c, where the pore edges are highlighted in red in Fig. S1d. The electrode porosity was thus estimated as a surface porosity considering the ratio of the segmented porosity by thresholding over the total image surface. 
Subsequently the size distribution of the pores was determined thanks to a local thickness measurement algorithm available in the ImageJ software [21]. The equivalent diameter of a pore was identified as the diameter of the largest sphere that fits inside the pore. The graphite phase, made up of the graphite active particles and the GnP conductive additive, was manually identified in order to evaluate the structural evolution of this phase, i.e. surface fraction and twisting of the graphite platelets, upon cycling. Some Si particles were also manually identified to evaluate the inter-particle distance evolution with cycling by tracking their displacement on different close-up SEM views.

\section{Results and discussion}

\subsection{Electrochemical behavior}

The evolution upon cycling of the discharge capacity and coulombic efficiency of the Si/graphite electrode studied by FIB/SEM is displayed in Figs. 2a and $\mathbf{2 b}$, respectively. The FIB/SEM acquisition steps are labeled with green stars in Fig. 2a. The discharge/charge voltage profiles and corresponding differential capacity plots for the $1^{\text {st }}, 9^{\text {th }}$ and $50^{\text {th }}$ cycles are shown in Figs. 2c and d, respectively. The initial discharge (charge) capacity is 2040 (1706) $\mathrm{mAh} \mathrm{g}^{-1}$, which is close to the theoretical capacity of $1976 \mathrm{mAh} \mathrm{g}^{-1}$ (calculated with $3579 \mathrm{mAh} \mathrm{g}^{-1}$ for $\mathrm{Li}_{15} \mathrm{Si}_{4}$ and $372 \mathrm{mAh} \mathrm{g}^{-1}$ for $\mathrm{LiC}_{6}$ ), suggesting that all the $\mathrm{Si}$ and graphite particles in the electrode are electrochemically accessible. One must however note that a fraction of this initial discharge capacity is also related to the SEI formation, which consumes electrons through the electroreduction of the electrolytic solution [22]. The initial coulombic efficiency (CE) is $83.6 \%$, corresponding to an irreversible capacity loss (ICL) of $334 \mathrm{mAh} \mathrm{g}^{-1}$. This ICL value is far below those usually reported for graphite-free Si-based electrodes (e.g. ICL of $1610 \mathrm{mAh} \mathrm{g}^{-1}$ for a 
$\mathrm{Si} / \mathrm{GnP} / \mathrm{PAA}\left(83 / 13 / 4 \mathrm{wt} . \%\right.$ ) electrode with a $\mathrm{Si}$ areal mass loading of $2.5 \mathrm{mg} \mathrm{cm}^{-2}$ [23]). The CE at the second cycle is $85.9 \%$, which is surprisingly lower than other reported values for $\mathrm{Si} / \mathrm{Gr}$ composite electrodes. This difference is probably related on the one hand to the electrode dismantling and rinsing procedure, which leads to partial dissolution/peeling of the previously formed SEI layer, and on the other hand to the FIB milling step, which reveals fresh anode material leading to eventual new SEI formation. This cost can be estimated at $242 \mathrm{mAh} \mathrm{g}^{-1}$ given the fact that a part of this value is also related to possible electrical disconnection in the electrode's bulk. The discharge capacity measured at the $50^{\text {th }}$ cycle is $1180 \mathrm{mAh} \mathrm{g}^{-1}$, corresponding to a capacity decay of $42 \%$, which is indicative of major electrode degradation upon cycling. The dismantling and electrode rinsing procedures for the FIB/SEM acquisitions also induce a loss of capacity as highlighted by the CE drop of $\sim 7 \%$ observed at the $10^{\text {th }}$ cycle (Fig. 2b) resulting in a discharge capacity loss of $\sim 100 \mathrm{mAh} \mathrm{g}^{-1}$ at the $11^{\text {th }}$ cycle (Fig. 2a). However, the mean capacity decay rate per cycle is quite similar before and after this event (i.e. $\sim 5 \mathrm{mAh} \mathrm{g}^{-1}$ per cycle), suggesting that the FIB/SEM analyses do not affect significantly the global behavior of the electrode. As a reference and in order to highlight more clearly the impact of the acquisition procedure, a Si/Gr anode with similar active material loading has been cycled in a coin cell. The comparative analysis is presented in the supplementary information (Fig. S2).

As seen in the voltage profiles (Fig. 2c), there is a decrease of the discharge potential as the cycle number increases, which is indicative of an increasing electrode polarization with cycling. As a result, the lithiation of the Si phase becomes less deep, limiting the formation of the c$\mathrm{Li}_{15} \mathrm{Si}_{4}$ phase as evidenced by the disappearance on the differential capacity plot (Fig. $\left.\mathbf{2 d}\right)$ of the sharp anodic peak at $460 \mathrm{mV}$, which is characteristic of the delithiation of the c- $\mathrm{Li}_{15} \mathrm{Si}_{4}$ phase [24]. On the other hand, an increase of the broad anodic peak at $\sim 0.3 \mathrm{~V}$ attributed to the 
delithiation of a- $\mathrm{Li}_{3.5} \mathrm{Si}$ to $\mathrm{a}-\mathrm{Li}_{2.0} \mathrm{Si}$ [25] is observed. Two anodic peaks related to lithium deintercalation from graphite [26] are also observed around 140-180 mV (see insert in Fig. 2d). It is worth noticing that their magnitude decreases with the increasing cycle number, especially for the peak situated at $140 \mathrm{mV}$ corresponding to the conversion of $\mathrm{LiC}_{6}$ to $\mathrm{LiC}_{12}$, which has almost vanished at the $50^{\text {th }}$ cycle. This means that the electroactivity of the graphite component in the Si/graphite electrode is also significantly affected with cycling, potentially linked with an increase in the cell impedance thus hindering the reaction $\mathrm{LiC}_{12} \rightarrow \mathrm{LiC}_{6}$ that occurs at the lowest potential.

(a)

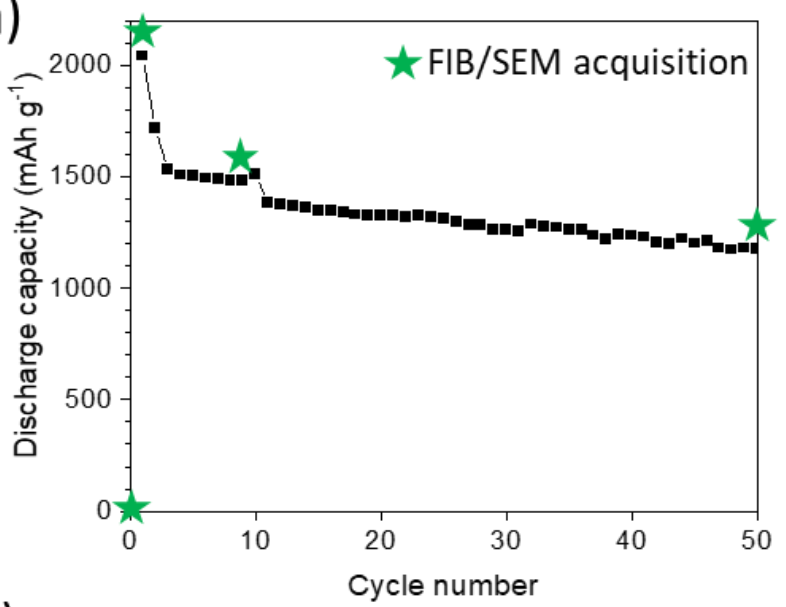

(c)

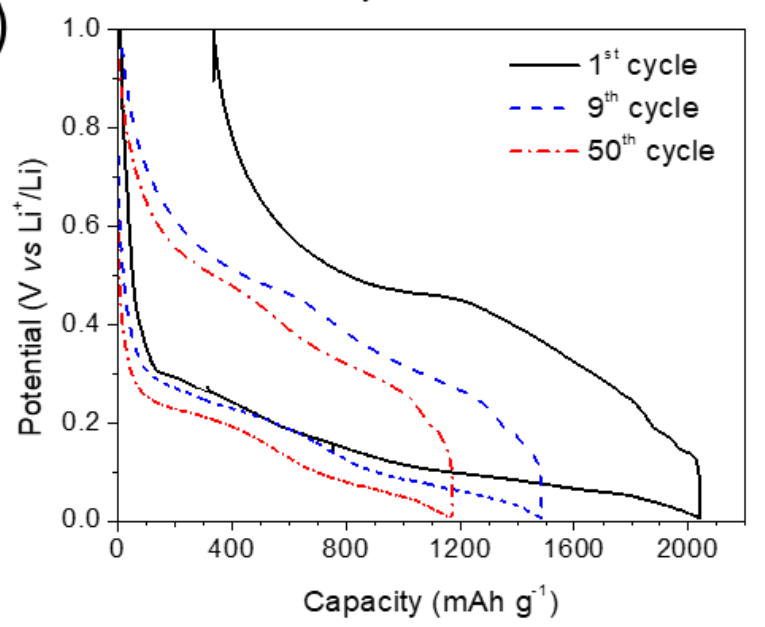

(b)

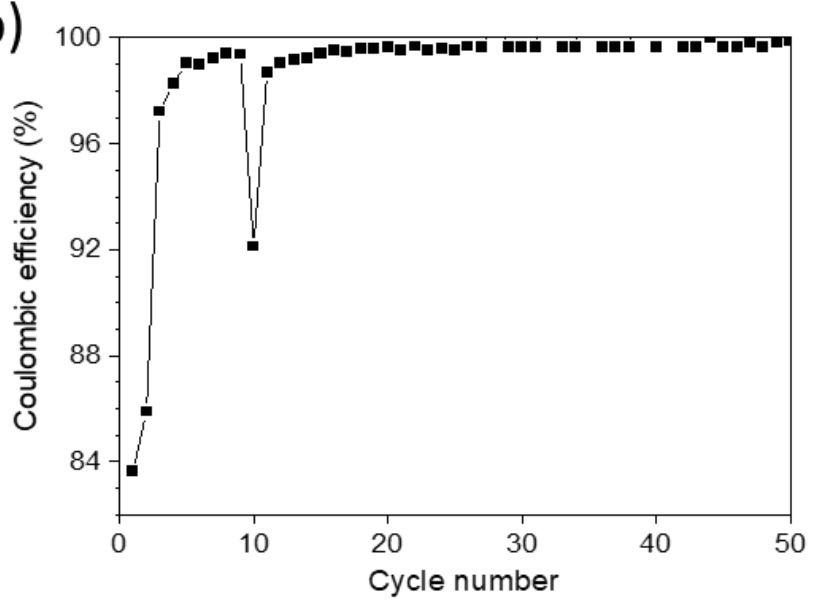

(d)

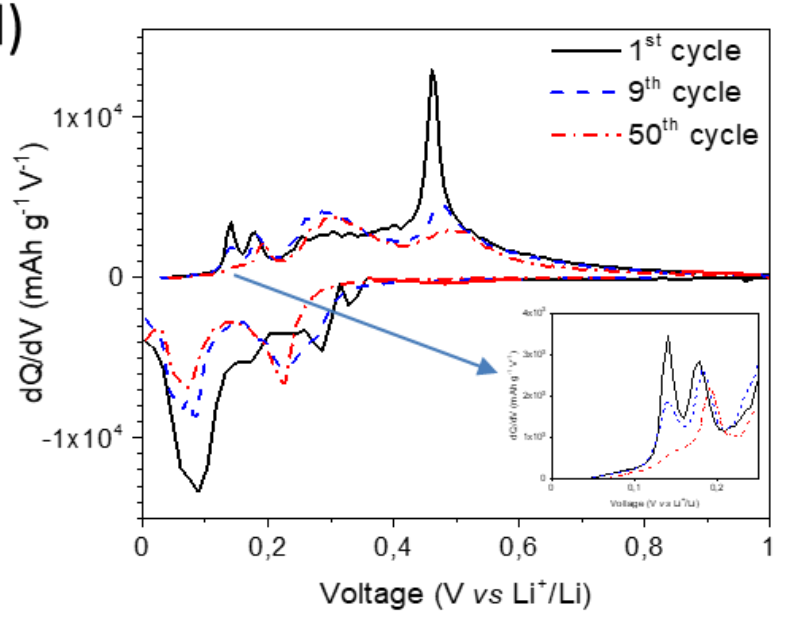

Figure 2. Evolution of the (a) discharge capacity and (b) coulombic efficiency with cycling, (c) voltage profiles and $(d)$ corresponding differential capacity plots for the $1^{\text {st }}, 9^{\text {th }}$ and $50^{\text {th }}$ cycles of the Si/graphite electrode. 
EIS measurements were done on a sister electrode in its pristine state and with cycling, at potentials selected according to the electrochemical activity of silicon and graphite [27], as identified on the differential capacity plots (see supplementary Fig. S3a). Prior to cycling, a first EIS measurement was taken at $3 \mathrm{~V}\left(v s . \mathrm{Li}^{+} / \mathrm{Li}\right)$ as a reference. Then, in the course of lithiation, EIS acquisitions were taken at $0.4,0.15$ and $0.005 \mathrm{~V}$. A final acquisition was taken after delithiation at $1 \mathrm{~V}$, i.e. at the end of the $1^{\text {st }}$ cycle. This was repeated for the $2^{\text {nd }}, 3^{\text {rd }}, 10^{\text {th }}, 20^{\text {th }}$, $30^{\text {th }}, 40^{\text {th }}$ and $50^{\text {th }}$ cycles. Selected Nyquist plots are shown in supplementary Fig. S3b. As usually observed, the spectra are composed of semicircular components in the middle-frequency region $(\sim 10 \mathrm{~Hz}-100 \mathrm{kHz})$ and a Warburg linear part in the low-frequency region (below $\sim 10$ $\mathrm{Hz})[\mathbf{1 6 , 2 8 , 2 9}]$. The position of the high frequency intercept of the EIS spectra is influenced by the experimental set-up (uncertain cable and connection resistance) and is thus not discussed hereafter. Generally, the middle-frequency region of the Nyquist plot is fitted with one or two resistance//pseudo-capacitance elements to model the charge-transfer and the SEI layer contributions [16,28]. More complex circuit models are needed to take into account additional contributions of the ionic and electronic path resistances across composite electrodes, including the contact resistance at the electrode/current collector interface [29]. Furthermore, the deconvolution of the spectra into these different contributions requires carrying out additional hypotheses or experiments to ensure the results. Therefore, the analysis is done here by focusing on the globalized resistance of the semi-circular arc in the middle-frequency region, defined by the difference between its two intercepts with the $x$ axis. This total resistance globalizes the four contributions listed above. The results are plotted in Fig. 3. 
(a)

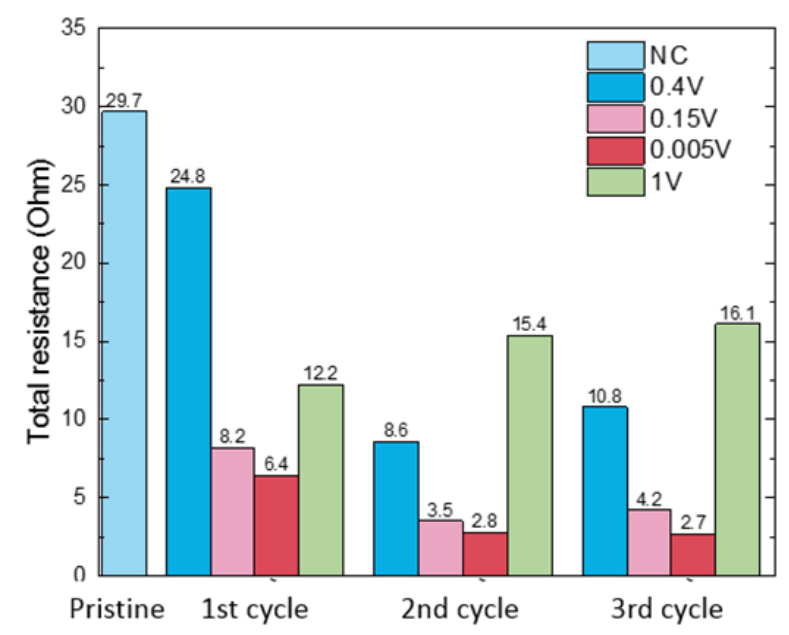

(b)

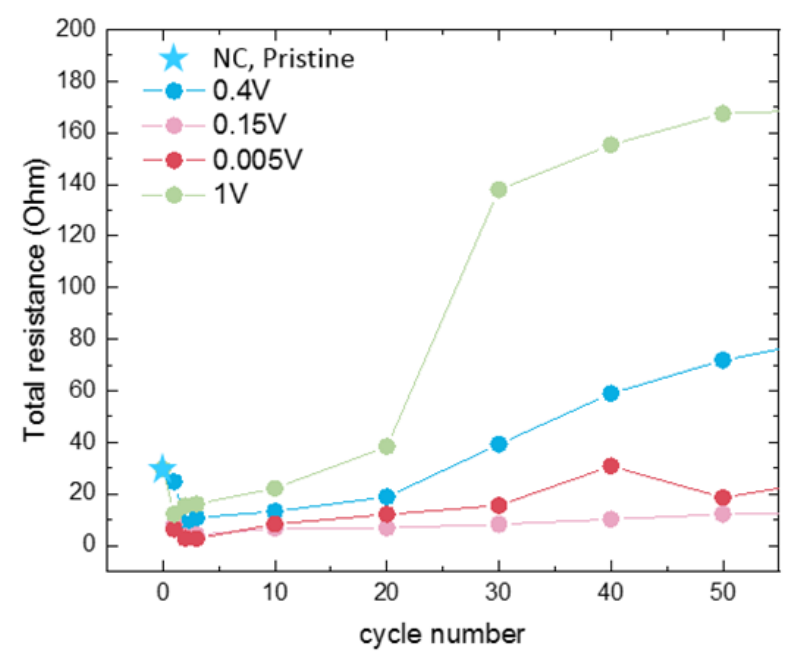

Figure 3. Evolution of the electrode resistance measured at the OCP in pristine state, at 0.4, 0.15 , and $0.005 \mathrm{~V}$ in lithiation and $1 \mathrm{~V}$ in delithiation (a) over the three first cycles and $(b)$ over 50 cycles.

Fig. 3a is focused on the first 3 cycles. From the pristine state, a decrease in resistance is observed with lithiation. Indeed, its value drops from about $30 \mathrm{ohms}$ at the OCV to $6.4 \mathrm{ohms}$ at $0.005 \mathrm{~V}$. This behavior has already been observed [28]. It could be attributed on the one hand to an improvement in the electronic transfer in the electrode following the increase in pressure inside the electrochemical cell, because the expansion of the electrode takes place in a closed space, resulting in a decrease in contact resistance between the particles and the current collector. On the other hand, there is an increase in the conductivity of silicon when the latter forms alloys with lithium. With the delithiation and contraction of the electrode, it is observed that the total resistance increases again. It is equal to $12.2 \mathrm{ohms}$ at $1 \mathrm{~V}$, i.e. at the end of the first cycle. During the second cycle, we find again the same tendency. The resistance decreases during lithiation from $1 \mathrm{~V}$ to $0.005 \mathrm{~V}$, then increases again during delithiation. However, the values measured for each potential are lower during the second cycle than those of the first cycle. It is possible to attribute this result to a settlement of the electrode during the first cycle. The electrode was not calendared after its manufacture. Thus, during the first expansion of the electrode (in the first 
cycle), as this is done in a restricted volume, it is possible that this is accompanied by a reorganization of the arrangement of the particles submitted to compressive stress.

In subsequent cycles (Fig. 3b), this same trend of decreasing resistance during lithiation and re-increasing during delithiation is maintained. We observe, nevertheless, that the resistance at $0.005 \mathrm{~V}$ is slightly higher than that at $0.15 \mathrm{~V}$. However, the most striking evolution is that from the second cycle the resistance increases with the increase in the number of cycles, and this whatever the potential at which it is measured. This increase in impedance is attributable to the accumulation of electrolyte degradation products on the surface of the active material, more particularly silicon, which penalizes the charge transfer reaction as well as electronic transfer and the transport of lithium in the electrode $[8, \mathbf{1 6 , 2 8 , 2 9 ]}$. The mechanical degradation of the electrode, with the appearance of cracks, or the loss of adhesion with the current collector are other reasons which can be at the origin of this increase in impedance [9]. The sudden increase in the impedance between the $20^{\text {th }}$ and $30^{\text {th }}$ cycles could reflect an accentuation in mechanical/morphological degradation of the electrode. However, it should be noted that this increase in impedance is only marked at $1 \mathrm{~V}$, and to a lesser extent at $0.4 \mathrm{~V}$, whereas the resistance evolution measured at $5 \mathrm{mV}$ (i.e. in fully discharged state) is more progressive and consistent with the steady discharge capacity decay previously reported in Fig. 2a. Thus, this important resistance increase should be primarily considered as a sign of major degradation of the electrode. Since many assumptions can be made to interpret the changes during cycling of the electrode impedance studied here, the characterization of changes in its microstructure is clearly necessary to validate these assumptions. 


\subsection{Morphological evolution}

\subsubsection{At the electrode scale}

Fig. 4a shows the Si/graphite electrode cross section $\left(45 \times 75 \mu \mathrm{m}^{2} \times 50 \mu \mathrm{m}\right.$ depth initially) in its pristine state and after the cell dismantling at the end of the $1^{\text {st }}$ and $9^{\text {th }}$ cycles. Fig. $4 \mathbf{b}$ shows the $\mathrm{Si} /$ graphite electrode cross section of Fig. 4a after fine FIB polishing for restoring the analyzed surface at the three first steps of cycling. In its pristine state, the electrode thickness is $44 \mu \mathrm{m}$ and its microstructure seems homogeneous on the large scale over the whole electrode thickness. After the $1^{\text {st }}$ cycle, the residual electrode inflation is visible on the trench walls, especially on the left side. This is even more pronounced after the $9^{\text {th }}$ cycle, where this irreversible expansion can be seen on both sides accompanied with the collapse of the left trench wall. In addition, a crack visible at the left corner of the polished cross section, formed after the $1^{\text {st }}$ cycle, is then subsequently filled after 9 consecutive cycles, underlining the cumulated irreversible changes. The electrode surface presents some separator fiber imprints after nine cycles as evidenced by the image of Fig. $4 \mathbf{a}$ at the $9^{\text {th }}$ cycle (at its bottom right) and the remaining fibers on the image at the $1^{\text {st }}$ cycle, highlighting the important constraint applied on the electrode and the separator while the lithiation is ongoing. With cycling, the electrode thickness increases, to reach $120 \mu \mathrm{m}$ at the $50^{\text {th }}$ cycle as a consequence of the cumulated irreversible volume changes.

In order to quantify more precisely these changes, the mass of the electrode along with its porosity and thickness have been followed over 50 cycles. Their relative evolutions are presented in Fig. 5a and, the pore size distribution at each step is reported in Fig. 5b. Complementarily, the 
thickness, weight and porosity values of the electrode at the pristine state and after the $1^{\text {st }}, 9^{\text {th }}$ and $50^{\text {th }}$ cycles are reported in Table $\mathbf{S 1}$ in supplementary information.
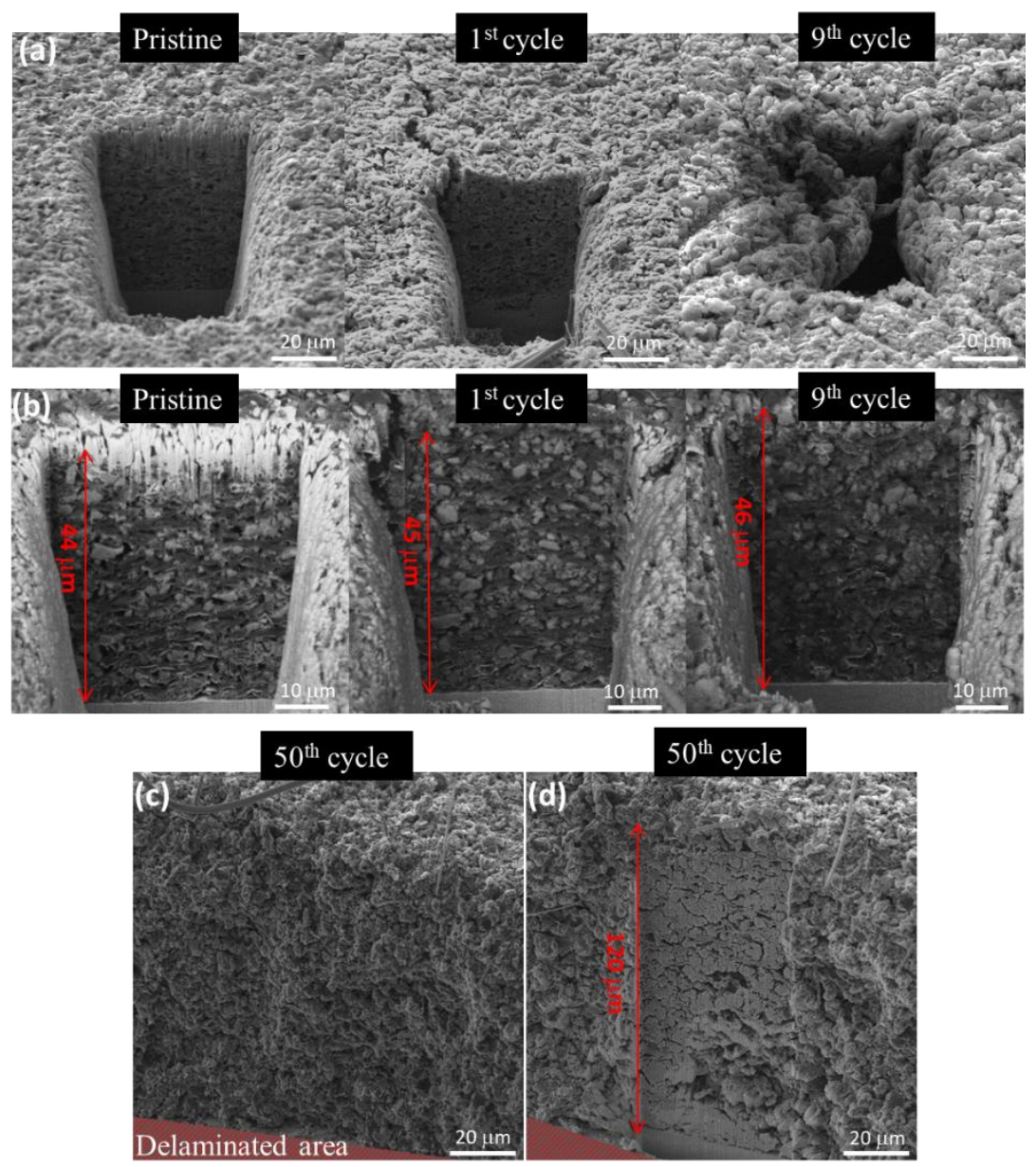

Figure 4. SEM images of the FIB-milled trench of the Si/graphite electrode $(a, c)$ before and $(b$, d) after FIB fine polishing; At the $50^{\text {th }}$ cycle, the electrode partially delaminated and thus a different observation zone was chosen. 
(a)

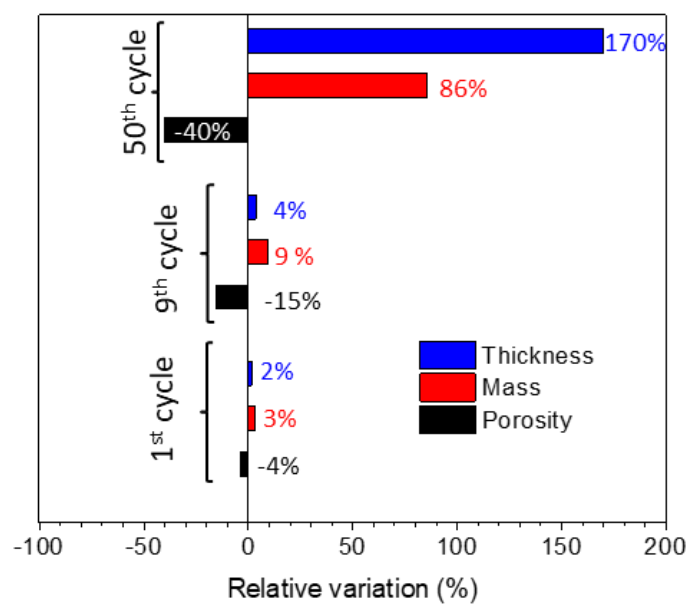

(b)

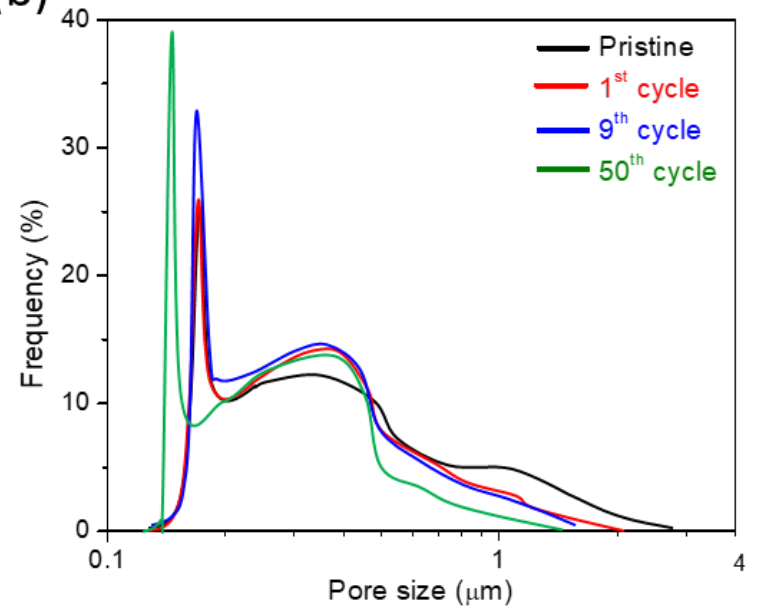

Figure 5. (a) Relative variation with cycling of the electrode thickness, mass, and porosity and (b) evolution of the pore size distribution with cycling

After the $1^{\text {st }}$ cycle, there is no major change in terms of electrode thickness $(+2 \%)$, mass $(+3 \%)$, porosity $(-4 \%)$ and pore size distribution. This suggests that the morphological evolution of the Si/graphite electrode is very limited after one cycle. This strongly differs from the behavior of graphite-free $\mathrm{Si}$ based electrodes in which major irreversible expansion, macrocracking and delamination from the $\mathrm{Cu}$ current collector were observed during the $1^{\text {st }}$ cycle by in-situ X-ray tomography [9]. Thus, the decrease of the Si amount in the electrode (43 wt.\% in the present case $v s .73$ wt.\% in ref. 9), inducing a lower global volume expansion/contraction of the electrode, prevents its decohesion/delamination during the $1^{\text {st }}$ cycle. However, this does not preclude major capacity decay (Fig. 2a) and low CE values (Fig. 2b) during the first cycle, which must mainly originate from the initial formation of the SEI layer on the fresh active material.

After 9 cycles, the irreversible increase of electrode thickness stays very limited $(+4 \%)$. A decrease of the electrode porosity is observed (-15\%), with no major change in the pore size distribution except a slight increase in the fraction of the small pores (see blue curve in Fig. 5b). This implies a densification of the electrode inner structure. This can be correlated to the 
electrode mass gain $(+9 \%)$ observed after 9 cycles. It is reasonable to assume that this mass gain is mainly linked to the continuous accumulation of insoluble electrolyte degradation products in the electrode pores due to the instability of the SEI layer on the Si particles $[\mathbf{1 6 - 1 8 , 2 2}]$. As a result, lithium ion diffusion in the electrode is restricted, as well as the electrons transfer, inducing an increase of the electrode polarization and a decrease of the discharge capacity as shown in Fig. 2.

The electrode morphological aspect has drastically changed at the $50^{\text {th }}$ cycle, given the fact that it has not been possible to investigate the same area as for the nine first cycles because of important electrode delamination. Consequently, a different zone has been chosen for the FIB milling/polishing as shown in Fig. $\mathbf{4 c}$ and Fig. $\mathbf{4 d}$ (after coarse and then fine polishing). One can note the appearance of a large cavity at the bottom right of the imaged zone (Fig. 4d), which is most probably due to the electrode tearing and not to cycling-induced degradation. However, except for this large cavity, the remaining porosity of the electrode is strongly decreased (-40\%) (Fig. 5a) with the appearance of smaller pores (green curve in Fig. 5b). This observation confirms the extensive accumulation of SEI products in the porous network of the electrode with cycling as already observed at the $9^{\text {th }}$ cycle to a lesser extent. This is also supported by the important mass gain of $86 \%$ reported at the $50^{\text {th }}$ cycle. Additionally, there is a very large increase of the electrode thickness $(+170 \%$ or $+75 \mu \mathrm{m})$. This increase originates not only from the SEI layer thickening and the electrode decohesion as highlighted by the presence of a large cavity and cracks in the electrode (Fig. 4d), but also from an irreversible morphological evolution of the Si particles, as will be seen in the next section and in agreement with [16]. Wetjen et al. observed indeed the progressive transformation upon cycling of initially dense Si particles into nanoporous structures with a high surface area and large void spaces, resulting in a considerable 
irreversible particle expansion, accumulation of liquid electrolyte degradation products at the surface and within the nanopores, and irreversible electrode thickness increase.

It is worth noticing that the irreversible electrode thickness expansion rate from the $10^{\text {th }}$ to the $50^{\text {th }}$ cycle is about 10 time higher than from the $1^{\text {st }}$ and $9^{\text {th }}$ cycle $(4.0$ and $0.4 \%$ per cycle, respectively) whereas its mass gain rate is quite stable (1-2\% per cycle over 50 cycles). This dramatic increase in the thickness of the electrode is concomitant with the dramatic increase in the impedance of the electrode between the $20^{\text {th }}$ and the $30^{\text {th }}$ cycle in the delithiated $(1.0 \mathrm{~V})$ or weakly lithiated $(0.4 \mathrm{~V})$ states as highlighted in Fig $\mathbf{3 b}$. A possible explanation is that during prolonged cycling, the SEI layer becomes too thick to be buffered in volume by the electrode porosity and then its growth induces the rupture of the PAA binder bounds, diminishing the mechanical strength of the electrode, which results in its decohesion and an accentuation of its irreversible expansion. The poor residual mechanical strength of the electrode was also evidenced by its partial delamination during its manipulation after dismantling the cell at the $50^{\text {th }}$ cycle. However, despite the loss of electrode cohesion and adhesion during prolonged cycling, there is no significant increase in the capacity decay rate from the $11^{\text {th }}$ to the $50^{\text {th }}$ cycle (Fig. 2a). This implies that the cell compression must have a key role in maintaining the electrical contacts in the Si/graphite electrode in spite of its major morphological variation and decreased mechanical strength. This is also in agreement with the slight changes of the electrode resistance measured at $5 \mathrm{mV}$ (Fig. 3b).

\subsubsection{At the silicon/graphite particle scale}

In order to provide a deeper understanding of the irreversible morphological changes undergone by the electrode, the evolution of the inter-particle distance is estimated by tracking 
the Si particle displacement on different close-up views of the FIB-polished cross section. Three different observation areas have been chosen (Fig. 6b-c): two at the same electrode height (zones 1 and 2), and one closer to the current collector (zone 3), on which four different Si particles have been selected at the pristine state (labeled A to D accordingly to their initial height position). At each step of the cycling, the distances between the four Si particles, i.e. $\mathrm{d}_{\mathrm{A}-\mathrm{B}}, \mathrm{d}_{\mathrm{B}-\mathrm{C}}$, $\mathrm{d}_{\mathrm{C}-\mathrm{D}}, \mathrm{d}_{\mathrm{D}-\mathrm{A}}, \mathrm{d}_{\mathrm{B}-\mathrm{D}}$ and $\mathrm{d}_{\mathrm{C}-\mathrm{A}}$ are measured and averaged for each of the three areas in the electrode. Note that recording the milling procedure of the cycled electrode is mandatory for tracking the position of the selected silicon particles as shown in Video S2 and Fig. S4, in which the Si particles previous positions upon the milling step are highlighted. In fact, even if the Si particles appear to be largely eroded during the polishing step, their current position can be traced back according the provided video at the analyzed steps of the cycling. In addition, their direct surroundings (especially pores and graphite sheets) are used for identifying the same spots in the images. As an illustration, the pore at the interface with the current collector below the yellow particle of the Fig. 6c (zone3) has been useful to get back to the same area and recover the particle positions. This methodology is sufficient according to our view to monitor reliably the evolution of the inter-particle distances but cannot be applied in order to estimate the volume changes at the particle scale, which is difficult to estimate from the present FIB/SEM observations. The evolution of the averaged distance variation with cycling is reported in Fig. 6a. In order to depict the entire electrode behavior, a mean inter-particle value along the electrode and its standard deviation is also estimated and plotted in Fig. 6a (black diamond). Nonetheless, reserved should be taken while considering these relative inter-particle displacements. Indeed, the absence of constraint and possible changes in the local electric field due to the micro-cavity formed by the FIB milling for the electrode bulk observation might affect 
the particle rearrangements and distance changes evaluated in the present case. However, as the electrode morphological changes manifest mostly along its height, one could be confident about the conclusions draw from the inter-particle displacements evaluated here.

After the $1^{\text {st }}$ cycle, a reduction of the inter-particle distance is observed, reflecting a compressive behavior along the global electrode $(-6 \%)$ and more particularly in zones $1(-8 \%)$ and $3(-10 \%)$. Nonetheless, the opposite trend is observed in zone 2 with a $1 \%$ inter-particle distance elongation, thus underlining the heterogeneity of the morphological changes in the electrode. This can be correlated with the inherent heterogeneity of the electrode in the pristine state at a smaller scale, given the fact that the second area shows a higher initial graphite fraction (24\%) compared to the other analyzed areas $(18.5 \%)$. In fact, thanks to their platelet shape and lubricant properties, the graphite particles might favor the sliding of the Si particles, relaxing the mechanical stress within the electrode. The reduction of the inter-particle distance, on average, is very likely the cause of the decrease in the impedance of the electrode seen at the very start of cycling (Fig. 3a). As suggested above, this settlement of the electrode is likely to occur during the first cycle while the expansion of the silicon particles takes place in a space confined by the edges of the electrochemical cell and against the pressure exerted by the spring, which presses on the stack formed by the separator and the two electrodes [30]. Then after reaching nine cycles, the electrode presents an overall elongation of the Si inter-particle distances of $12 \%$, which is exacerbated in zone $2(23 \%)$ compared to the rest of the electrode (6-7\% for zones 1 and 3$)$. This can be explained through the progressive decrease in the electrode mobility linked to the irreversible porosity decrease of $-15 \%$ reported in Fig. 5a, which hinders the rearrangement of the silicon particles in the electrode and results in a thickness increase (4\%) and inter-particle distance growth. This could also be explained by the breaking of the bridges formed by the 
polymer binder following the repeated volume variations of the Si particles. The accumulation of tensile-contraction cycles would damage the binder bridges, reducing the capacity of the electrode to recover its initial dimension.

Overall, the tendency suggests an important inner mobility of the electrode, which might be favored by the graphite sheets. This is also highlighted in Fig. 6d, which presents the changes in the orientation of the diagonal lines $\mathrm{d}_{\mathrm{B}-\mathrm{C}}(\mathrm{red})$ and $\mathrm{d}_{\mathrm{D}-\mathrm{A}}$ (green) for the first cycles. It appears strikingly that the diagonal main orientation tends to become horizontal with cycling, suggesting a shearing movement in the electrode enhanced by the increased mobility of the electrode, which may be as a result of the binder bridge breakage. This implies that local displacements in the lateral directions of the electrode play a key role in the general arrangement of the Si particles. 

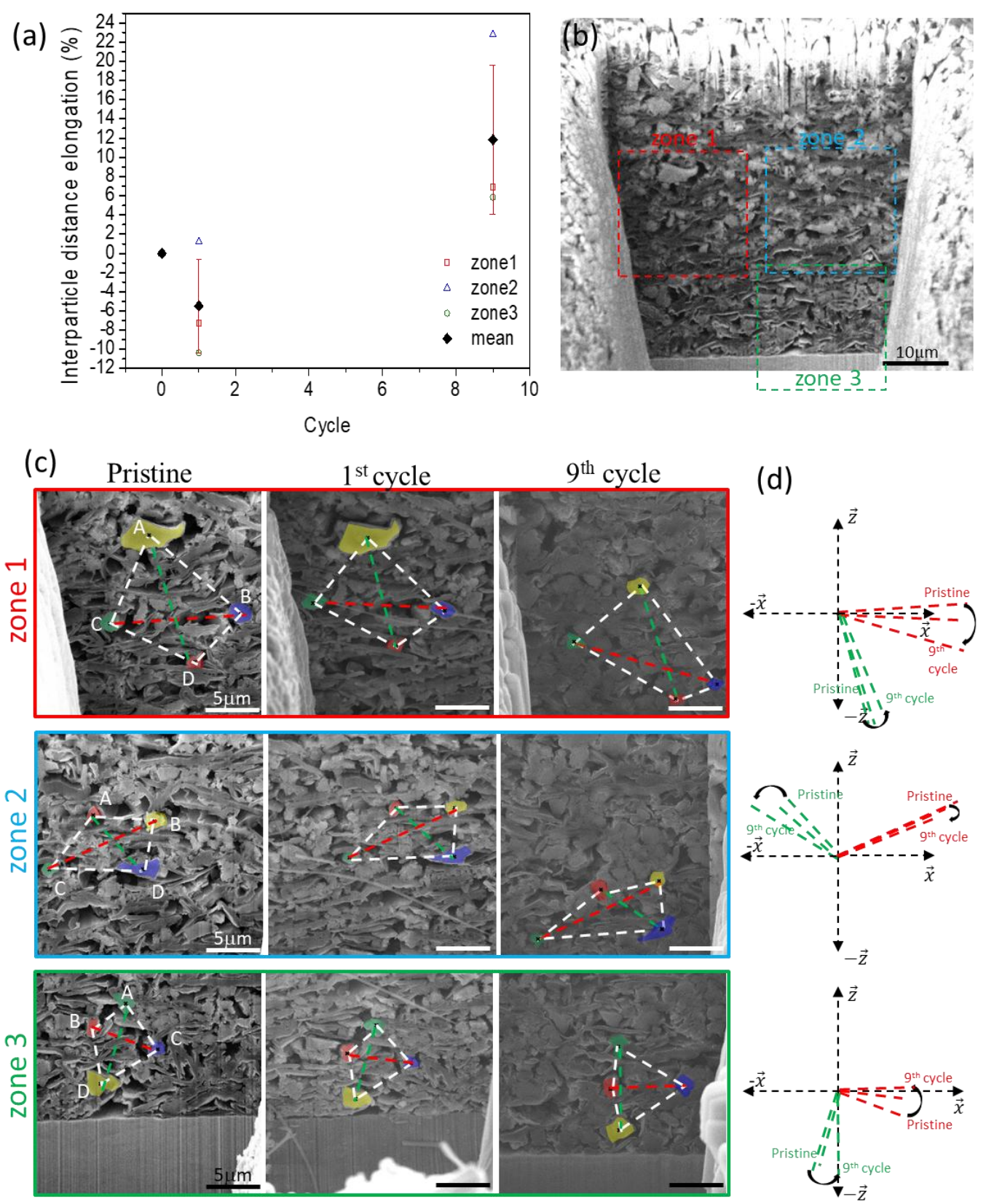

Figure 6. (a) Evolution of the Si interparticle distance with cycling; (b) Cross-section image of the electrode and (c) close-up views of the three different zones of $(b)$ with the tracked Si particles and (d) $2 D$ mapping of the orientation evolution of the $B C$ (red) and $A D$ (green) segments of (c) with cycling.

Moreover, the aspect and size of the Si particles change drastically during cycling. In fact, as the aging of the electrode progresses, the mean diameter of the Si particles at first decreases and then increases as shown in Fig. 7a. For supporting this, Figs. 7b and c present the different cross 
sections of the electrode upon cycling with close-up views of the Si particles. After the first cycle, no significant change is observed in the mean diameter of the Si particles $(0.79$ to 0.81 $\mu \mathrm{m})$. This may be related to the $90 \%$ amorphous structure of the pristine ball-milled Si powder, which is likely to increase its cracking resistance [31]. However, at the end of the $9^{\text {th }}$ cycle, the mean diameter of the Si particles is reduced to $0.66 \mu \mathrm{m}$, which represents a decrease of nearly $16 \%$ compared to the pristine state. This could be a result of the particle cracking after repetitive cycles of tensile stress and compressive constraint under lithiation/delithiation as reported in the literature [31-33]. This phenomenon is reversed during the cycling as evidenced by the $86 \%$ increase in the mean particle size after 50 cycles, and the fact that the dispersion of the Si particle size distribution narrows with cycling and seems to tend to a limit value of $1.5 \mu \mathrm{m}$. In fact, the clearly discernable segmented aspect of the Si particles is no longer observable, as the particles consist more of macro-aggregated nanoparticles with nanoporous channels around 0.05-0.1 $\mu \mathrm{m}$, counting for $14 \%$ of the residual porosity. Such a morphology was also observed by Radvanyi et al. [34] who attributed it to a possible sintering of the nanosized Si particles during prolonged cycling. Wetjen et al. [16] explain it differently. The roughening of the particle surface and formation of void spaces is intrinsic to the dealloying of silicon and lithium. "Dealloying is a common corrosion process which involves the selected dissolution of the more electrochemically active element, here lithium, from an alloy and results in the formation of a nanoporous structure of the more noble alloy constituent, here silicon". The formation of this nanoporosity results indubitably in an irreversible expansion at both the particle and electrode scales, as we also see here. However, in the present case, the increase of the Si "particle" size should be predominantly associated with the Si particle sintering with cycling with a volume expansion of 
$\sim 560 \%$ at the $50^{\text {th }}$ cycle estimated from their median diameters (Fig. 7a), even so both phenomena are playing a role.

(a)

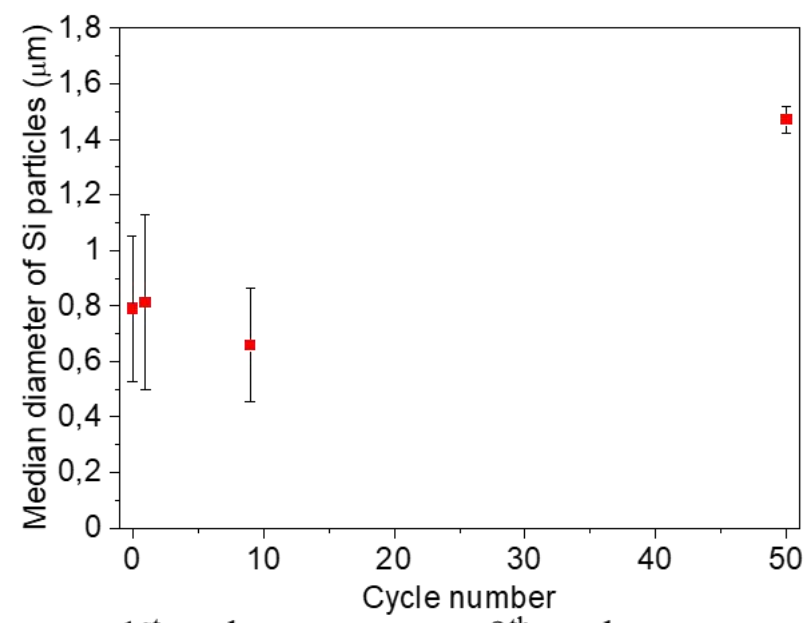

(b) Pristine

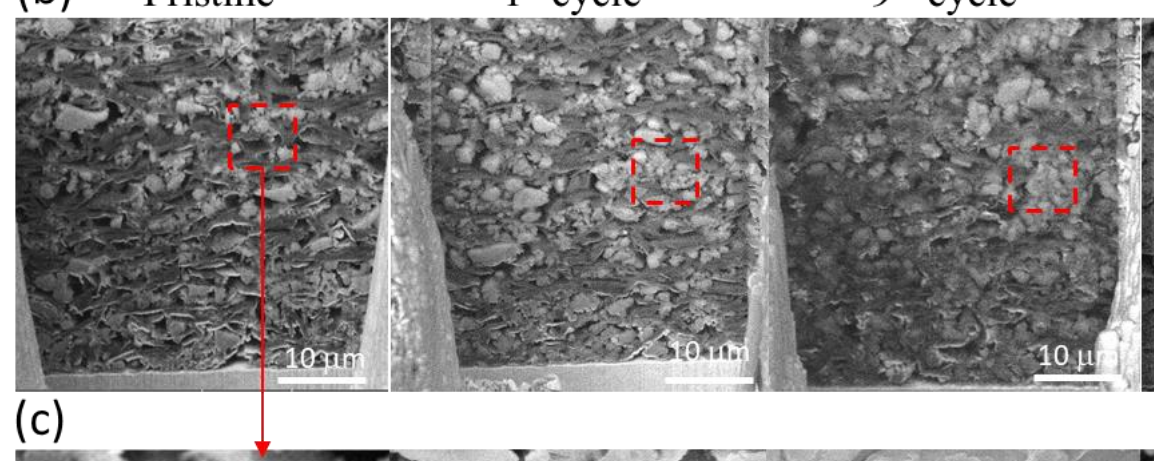

$50^{\text {th }}$ cycle

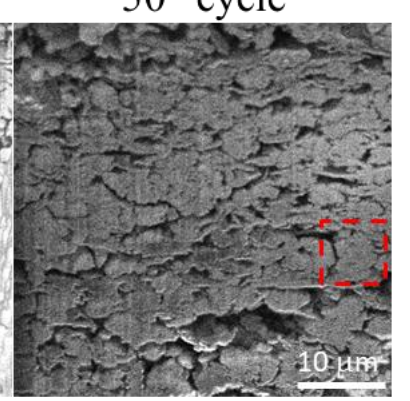

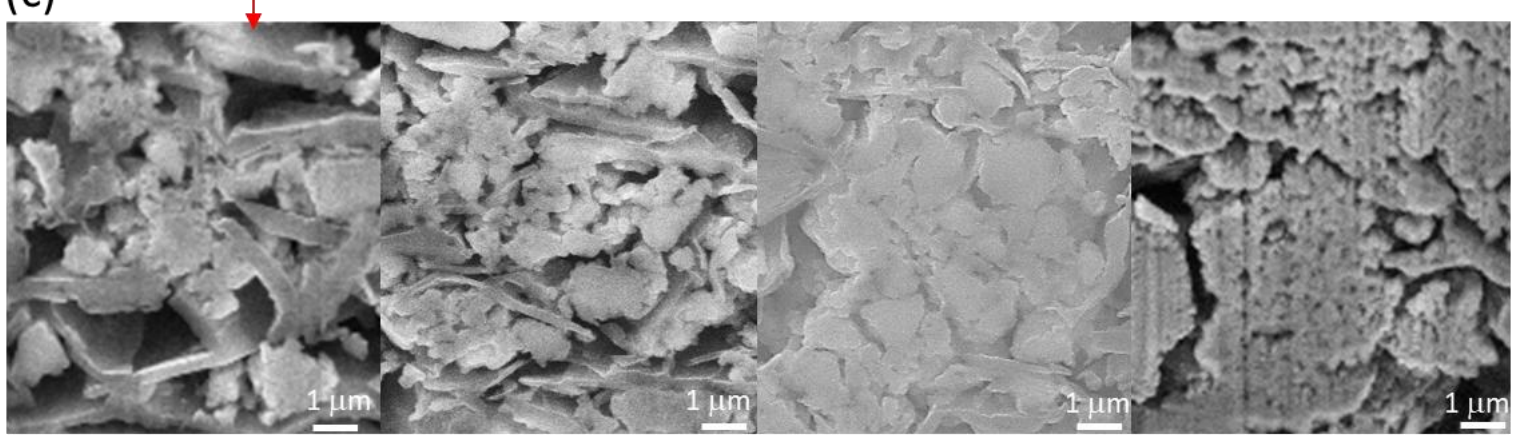

Figure 7. (a) Evolution of the median Si particle diameter with cycling; (b) cross-section SEM images of the pristine and cycled Si/graphite electrode and (c) zoom of the red dashed areas in (b).

In order to study the electrode mobility through the displacement of the graphite platelets, Fig. 8a presents qualitatively the evolution of the graphite content in zone 2 (except at the $50^{\text {th }}$ cycle). On the SEM images in Figs. $\mathbf{7 b}$ and $\mathbf{c}$, the platelet-shaped graphite particles are discernible via their darker grey level in the pristine state. The GnP conductive additive, 
consisting of stacks of graphene sheets $(\sim 5-15 \mu \mathrm{m}$ in length and $\sim 0.1-1 \mu \mathrm{m}$ in thickness) $[35,36]$, is hardly identifiable as their shape, dimensions and grey level are close to those of the graphite particles. Thus they are analyzed as a unique "graphite phase". Then, the evolution of the graphite surface fraction with cycling has been quantified (Fig. 8b) as well as the twisting of the graphite platelets (Fig. 8c). The latter is expressed as the ratio of twisted graphite sheets, which present an absolute curvature angle superior to $90^{\circ}$, over the total amount. A global displacement of the graphite flakes is observed, as evidenced by the $\sim 5 \mu \mathrm{m}$ right shift of the large graphite particle after one cycle, which was initially located in the upper left part of zone 2 shown in Fig. 8a. On the contrary, on the left side of the electrode (zone 1, not shown in Fig. 8a), a $\sim 3 \mu \mathrm{m}$ left shift is estimated from the graphite displacement. These opposite displacements tend to accentuate with cycling, suggesting the important shearing movement taking place in the electrode as previously reported in Fig. 6d. In the meantime, an important change of their morphology (size, shape) occurs as their surface fraction decreases from $20 \%$ (pristine) to $14 \%$ $\left(9^{\text {th }}\right.$ cycle) and subsequently to $6.5 \%\left(50^{\text {th }}\right.$ cycle), and the twisting increases from $6 \%$ (pristine) to $23 \%$ and then $29 \%$ at the $9^{\text {th }}$ and $50^{\text {th }}$ cycle, respectively. The important decrease of the graphite fraction might be associated with the large irreversible expansion of the silicon particles and the huge cumulated irreversible thickness expansion of the electrode $(+170 \%$ after 50 cycles). It can also be related to the fact that silicon particles and graphite flakes are hardly distinguished because they are both embedded in the SEI degradation products (see close-up views of Fig. 7c), especially after 50 cycles considering the important mass gain of $86 \%$. On the other hand, the twisting increase is a direct consequence of the important electrode rearrangement, thus showcasing the important mechanical constraints endured upon cycling. This tendency attenuates progressively with a limited increase of $6 \%$ from the $9^{\text {th }}$ to the $50^{\text {th }}$ cycle, compared to the two 
times higher value of $11 \%$ reported between cycles 1 and 9 . This can be paired with the inner mobility decrease of the electrode as its porosity decreases and its mass increases $(-40 \%$ and $+86 \%$ at the $50^{\text {th }}$ cycle, respectively). This phenomenon has a direct impact on the percolation path of the electrode and on the total resistance as was observed in the EIS experiments with their dramatic increase between the $20^{\text {th }}$ and the $30^{\text {th }}$ cycles, especially when silicon is in the delithiated state, i.e. the non-electrically conducting state (Fig. 3b). The very weak evolution of the electrode resistance measured at low potential, when the silicon is in a lithiated state, is an indirect proof of the increase in the electrical conductivity of silicon when it forms an alloy with lithium. Because then, electronic transfer can be ensured via the percolation of silicon particles.

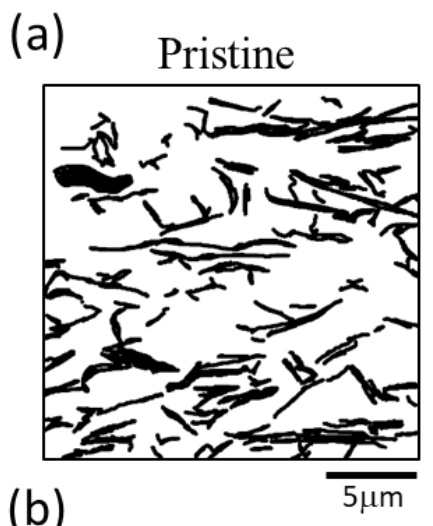

(b)

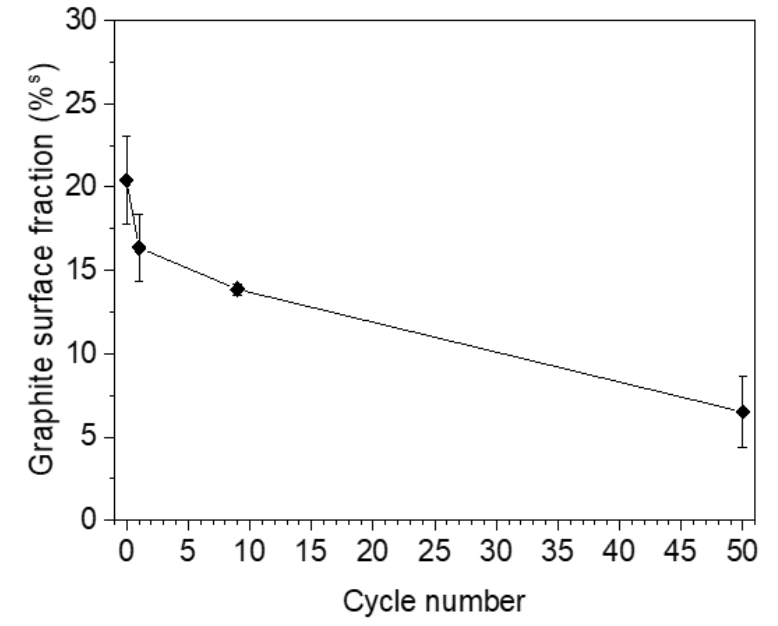


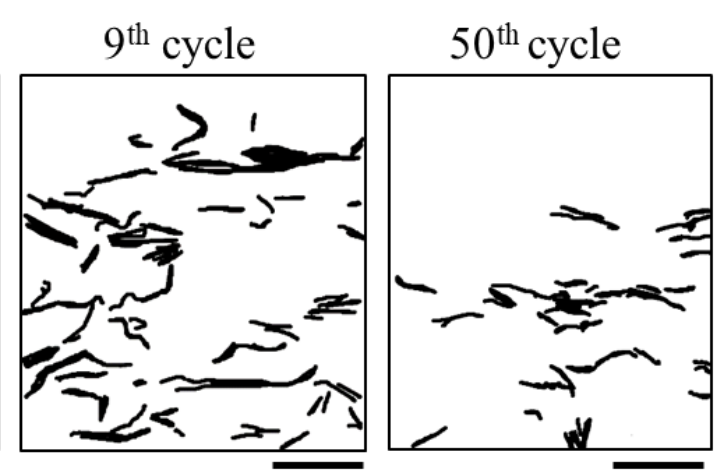

(c)

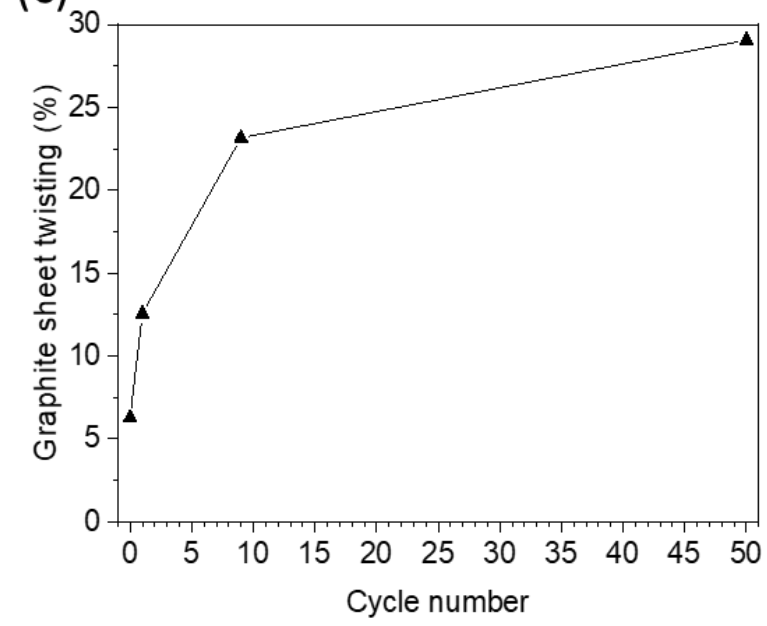

Figure 8. (a) Segmented binary images of the graphite flakes at each step of the cycling in zone 2 of the electrode (excluding the 50 ${ }^{\text {th }}$ where the analysed zone has been changed); $(b)$ associated evolution of the surface fraction and $(c)$ twisting rate of the graphite sheets. 


\section{Conclusions}

In the present study, an alternative procedure based on an FIB/SEM investigation of a single $\mathrm{Si} /$ graphite electrode at different steps of its cycling is demonstrated. This allows reducing the implementation cost compared to 3D FIB/SEM tomography and allows following the same electrode along different steps of its cycling, similar to an in-situ method. This ex-situ sequential FIB/SEM experiment is thus an efficient method for evaluating both qualitatively and quantitatively the degradation phenomena occurring in a Si/graphite blended electrode, for monitoring the morphological changes during its cycling and correlating them to its electrochemical behavior. This method has been demonstrated in a "worst-case scenario", considering the large electrode changes and rearrangements exhibited by the $\mathrm{Si} /$ graphite electrode, due to the Si intrinsic huge expansion/contraction upon lithion/delithiation. Despite the fact that the absence of constraints in one direction due to the FIB-milled micro-cavity might facilitate the local displacement of the Si particles, several striking observations have been highlighted:

(i) The electrode morphology (porosity, thickness and mass) stays barely unchanged after the $1^{\text {st }}$ cycle; this is major difference compared to a common Si-based electrode.

(ii) A contraction of the Si inter-particle distance is observed on average during the $1^{\text {st }}$ cycle, resulting in a decrease in the total resistance of the electrode. This contraction is attributed to the compressive effect exerted by the other components of the electrochemical cell on the $\mathrm{Si} /$ graphite electrode when the latter expands during lithiation. 
(iii) The graphite particles have a key role in releasing the inner constraints of the electrode and allowing structural rearrangement, which is important for the good cyclability of the electrode.

(iv) During the first 9 cycles, the lateral displacements of the silicon and graphite particles testify to shear (laminar) deformations within the electrode layer.

(v) The average size of the Si particles at first decreases and its dispersion narrows with the electrode cycling as a consequence of particle cracking; it then increases after 50 cycles, due to an important particle sintering along with their nanoporosification. At this point, the Si particles present a wrinkled structure with nanoporosity of 0.05 to $0.1 \mu \mathrm{m}$.

(vi) A major irreversible increase of the electrode thickness and an accumulation of electrolyte degradation products happen between the $10^{\text {th }}$ and the $50^{\text {th }}$ cycles, concomitantly with a dramatic evolution of the silicon from dense and small particles to large and nanoporous ones.

(vii) When silicon is alloyed with lithium (in the $0.15-0.005 \mathrm{~V}$ range), over 50 cycles the electrode resistance remains low reflecting the high electrical conductivity of $\mathrm{Li}_{x} \mathrm{Si}$ alloys. When silicon is not alloyed with lithium (in the $1.0-0.4 \mathrm{~V}$ range), the electrode resistance increases dramatically with cycling as the percolation of graphite particles is lost due to the presence of electrolyte degradation products and an irreversible increase of the electrode thickness.

Finally, this sequential FIB/SEM method could obviously be applied to other types of positive/negative electrodes for $\mathrm{Li}, \mathrm{Na}, \mathrm{K}, \mathrm{Ca}, \mathrm{Mg}, \mathrm{S} \ldots$ batteries to characterize their cycle- 
induced morphological evolution and to achieve a better understanding their degradation mechanisms.

\section{Acknowledgments}

The authors thank the Natural Sciences and Engineering Research Council (NSERC) of Canada (Grant No. RGPIN-2016-04524) for supporting this work. 


\section{Reference}

[1] R. Schmuch, R. Wagner, G. Hörpel, T. Placke, M. Winter, Performance and cost of materials for lithium-based rechargeable automotive batteries, Nat. Energy 3 (2018) 267278.

[2] D. Andre, S-J. Kim, P. Lamp, S. F. Lux, F. Maglia, O. Paschos, B. Stiaszny, Future generations of cathode materials: an automotive industry perspective, J. Mater. Chem. A 3 (2015) 6709-6732.

[3] M. Armand, P. Axmann, D. Bresser, M. Copley, K. Edström, C. Ekberg, D. Guyomard, B. Lestriez, P. Novak, M. Petranikova, W. Porcher, S. Trabesinger, M. Wohlfahrt-Mehrens, H. Zhang, Lithium-ion batteries - Current state of the art and anticipated developments, J. Power Sources 479 (2020) 228708.

[4] M.N. Obrovac, V.L. Chevrier, Alloy negative electrodes for Li-ion batteries, Chem. Rev. $114(2014) 11444$.

[5] M.N. Obrovac Review Article Si-alloy negative electrodes for Li-ion batteries, Current Opinion in Electrochemistry, 9 (2018) 8-17.

[6] Y. Jin, B. Zhu, Z. Lu, N, Liu, J. Zhu., Challenges and recent progress in the development of Si anodes for lithium-ion battery, Adv. Energy Mater. 7 (2017) 1700715.

[7] L. Y. Beaulieu, K. W. Eberman, R. L. Turner, L. J. Krause, J. R. Dahn, Colossal Reversible Volume Changes in Lithium Alloys, Electrochem. Solid-State Lett. 4 (2001) A137-A140.

[8] Y. Oumellal, N. Delpuech, D. Mazouzi, N. Dupré, J. Gaubicher, P. Moreau, P. Soudan, B. Lestriez, D. Guyomard The failure mechanism of nano-sized Si-based negative electrodes for lithium-ion batteries, J. Mater. Chem. 21 (2011) 6201-6208. 
[9] V. Vanpeene, J. Villanova, A. King, B. Lestriez, E. Maire, L. Roué, Dynamics of the morphological degradation of Si-based anodes for Li-ion batteries characterized by in-situ synchrotron X-ray tomography, Adv. Energy Mater. 9 (2019) 1803947.

[10] K. Eom, T. Joshi, A. Bordes, I. Do, T. F. Fuller, The design of a Li-ion full cell battery using a nano silicon and nano multi-layer graphene composite anode, J. Power Sources, 249 (2014) 118-124.

[11] S. D. Beattie, M. J. Loveridge, M. J. Lain, S. Ferrari, B. J. Polzin, R. Bhagat, R. Dashwood, Understanding capacity fade in silicon based electrodes for lithium-ion batteries using three electrode cells and upper cut-off voltage studies, J. Power Sources 302 (2016) 426-430.

[12] X. Shen, Z. Tian, R. Fan, L. Shao, D. Zhang, G. Cao, L. Kou, Y. Bai, Research progress on silicon/carbon composite anode materials for lithium-ion battery, J. Energy Chem. 27 (2018) 1067-1090.

[13] H. Buqa, M. Holzapfel, F. Krumeich, C. Veit, P. Novak, Study of styrene butadiene rubber and sodium methyl cellulose as binder for negative electrodes in lithium-ion batteries, J. Power Sources, 161 (2006) 617-622.

[14] T. Schott, R. Robert, S. P. Benito, P. A. Ulmann, P. Lanz, S. Zürcher, M. E. Spahr, P. Novák, S. Trabesinger, Cycling Behavior of Silicon-Containing Graphite Electrodes, Part B: Effect of the Silicon Source, J. Phys. Chem. C 121 (2017) 25718-25728.

[15] M. Sohn, D. G. Lee, D. J. Chung, A. Kim, H. Kim, Cycle-dependent Microstructural Changes of Silicon-Carbon Composite Anodes for Lithium-Ion Batteries, Bull. Korean Chem. Soc. 40 (2019) 150-156. 
[16] M. Wetjen, S. Solchenbach, D. Pritzl, J. Hou, V. Tileli, H. A. Gasteiger, Morphological Changes of Silicon Nanoparticles and the Influence of Cutoff Potentials in SiliconGraphite Electrodes, J. Electrochem. Soc. 165 (2018) A1503-A1514.

[17] S. Müller, P. Pietsch, B-E. Brandt, P. Baade, V. De Andrade, F. De Carlo, V. Wood, Quantification and modeling of mechanical degradation in lithium-ion batteries based on nanoscale imaging, Nat. Commun. 9 (2018) 2340.

[18] S. Müller, M. Lippuner, M. Verezhak, V. De Andrade, F. De Carlo, V. Wood, Multimodal Nanoscale Tomographic Imaging for Battery Electrodes, Adv. Energy Mater. 10 (2020) 1904119

[19] P. Pietsch, D. Westhoff, J. Feinauer, J. Eller, F. Marone, M. Stampanoni, V.Schmidt, V. Wood, Quantifying microstructural dynamics and electrochemical activity of graphite and silicon-graphite lithium ion battery anodes, Nat. Commun. 7 (2016) 12909.

[20] Hernandez, C. R. (2017). Étude d'électrodes négatives à base de Si pour batteries Li-ionMise en évidence d'un processus de maturation du film sous atmosphère humide, Master Thesis, INRS.

[21] J. Schindelin, I.Arganda-Carreras, E. Frise, V. Kaynig, M. Longair, T. Pietzsch, S. Preibisch, C. Rueden, S. Saalfeld, B. Schmid, J.-Y. Tinevez, D. J. White, V. Hartenstein, K. Eliceiri, P. Tomancak, A. Cardona, Fiji: an open-source platform for biological-image analysis, Nat. Methods 9 (2012) 676-682.

[22] D. Mazouzi, N. Delpuech, Y. Oumellal, M. Gauthier, M. Cerbelaud, J. Gaubicher, N. Dupré, P. Moreau, D. Guyomard, L. Roué, B. Lestriez, New insights into the siliconbased electrode's irreversibility along cycle life through simple gravimetric method, J. Power Sources 220 (2012) 180-184. 
[23] Z. Karkar, D. Guyomard, L. Roué, B. Lestriez, A comparative study of polyacrylic acid (PAA) and carboxymethyl cellulose (CMC) binders for Si-based electrodes, Electrochim. Acta 258 (2017) 453-466.

[24] J. Li, J. R. Dahn, An in situ X-ray diffraction study of the reaction of Li with crystalline Si, J. Electrochem. Soc. 154 (2007) A156-A161.

[25] K. Ogata, E. Salager, C.J. Kerr, A.E. Fraser, C. Ducati, A.J. Morris, S. Hofmann, C.P. Grey, Revealing lithium-silicide phase transformations in nano-structured silicon-based lithium ion batteries via in situ NMR spectroscopy, Nature Comm. 5 (2014) 3217.

[26] M. D. Levi, D. Aurbach, Simultaneous measurements and modeling of the electrochemical impedance and the cyclic voltammetric characteristics of graphite electrodes doped with lithium, J. Phys. Chem. B 101 (1997) 4630-4640.

[27] K. P. C. Yao, J. S. Okasinski, K. Kalaga, J. D. Almer, D. P. Abraham, Operando Quantification of (De)Lithiation Behavior of Silicon-Graphite Blended Electrodes for Lithium-Ion Batteries, Adv. Energy Mater. 2019, 1803380

[28] R. Ruffo, S. S. Hong, C. K. Chan, R. A. Huggins, Y. Cui, Impedance Analysis of Silicon Nanowire Lithium Ion Battery Anodes, J. Phys. Chem. C 2009, 113, 11390-11398

[29] Z. Yan, C. Wei, M. N. Obrovac, Understanding interfacial impedance growth in porous electrodes containing blended active materials, J. Power Sources 438 (2019) 226955

[30] V. Müller, R-G. Scurtu, K. Richter, T. Waldmann, M. Memm, M. A. Danzer, M. Wohlfahrt-Mehrens, Effects of Mechanical Compression on the Aging and the Expansion Behavior of Si/C-Composite|NMC811 in Different Lithium-Ion Battery Cell Formats, J. Electrochem. Soc. 166 (2019) A3796 
[31] M. T. McDowell, S. W. Lee, J. T. Harris, B. A. Korgel, C. Wang, W. D. Nix, Y. Cui, In situ TEM of two-phase lithiation of amorphous silicon nanospheres. Nano Letters, 13 (2013) 758-764.

[32] X. H. Liu, L. Zhong, S. Huang, S. X. Mao, T. Zhu, J. H. Huang, Size-dependent fracture of silicon nanoparticles during lithiation, ACS Nano 6 (2012), 1522-1531.

[33] J. W. Choi, D. Aurbach, Promise and reality of post post-lithium-ion batteries with high energy densities, Nature Review Materials 1 (2016) 16013.

[34] E. Radvanyi, W. Porcher, E. De Vito, A. Montani, S. Franger, S. J. S. Larbi, Failure mechanisms of nano-silicon anodes upon cycling: an electrode porosity evolution model, Phys. Chem. Chem. Phys. 16 (2014) 17142-17153.

[35] V. Vanpeene, A. King, E. Maire, L. Roué, In situ characterization of Si-based anodes by coupling synchrotron X-ray tomography and diffraction, Nano Energy 56 (2019) 799_ 812.

[36] Z. Karkar, D. Mazouzi, C. Reale Hernandez, D. Guyomard, L Roué, B. Lestriez, Threshold-like dependence of silicon-based electrode performance on active mass loading and nature of carbon conductive additive, Electrochim. Acta 215 (2016) 276-288. 